\title{
Effect of heme oxygenase-endogenous carbon monoxide on mortality during septic shock in rats
}

\author{
J.-b. Yu $\cdot$ S.-l. Yao
}

Received: 26 March 2008 / Accepted: 31 October 2008/Published online: 4 December 2008

(c) The Author(s) 2008. This article is published with open access at Springerlink.com

\begin{abstract}
Aim To investigate the effect of $\mathrm{HO}-\mathrm{CO}$ on mortality during septic shock in rats.

Method Eighty rats were randomly divided into groupcontrol, group ZnPP-IX, group SS, and group LZ.

Results Death was significantly lower in group SS than in group LZ $(P<0.05)$. The MAP was significantly higher in the group LZ than in the group SS $(P<0.05)$. ALT, AST, $\mathrm{Cr}$ and BUN, MDA, and the lung EB contents, were significantly lower in the group SS than that in the group LZ (all $P<0.05$ ). And CO and SOD activities were significantly higher in group SS than that in the group LZ (all $P<0.05$ ). HO-1 mRNA, and HO-1 protein were significantly lower in the group LZ than in the group SS $(P<0.05)$, whereas HO-2 mRNA, and HO-2 protein were not significantly different among four groups (all $P>0.05)$.

Conclusion The increased oxidative stress and end-organ damage is related to mortality during septic shock; while the hypotension partly contributing to HO-1 protein and $\mathrm{CO}$ has no obvious relation with it.
\end{abstract}

Keywords Septic shock · Heme oxygenase · Carbon monoxide $\cdot$ Hypotension $\cdot$ Mortality

\footnotetext{
J.-b. Yu ( $\square)$

Department of Anesthesiology, Tianjin Nankai Hospital, 300100 Tianjin, China

e-mail: jianboyu99@yahoo.com.cn

S.-1. Yao

Department of Anesthesiology, Union Hospital, Tongji Medical College, Huazhong University of Science and Technology, 430022 Wuhan, China
}

\section{Introduction}

Septic shock is initiated by the release of bacterial cell wall-derived lipopolysaccharide. If left unchecked, this process may progress to refractory hypotension, multiple organ system failure, and death. Beyond refractory hypotension, oxygen-derived free radicals are believed to contribute to the cellular and tissue injuries associated with endotoxin-induced inflammation. Investigators have suggested that this oxidative damage may be a major cause of organ failure and mortality associated with sepsis [1] and that the administration of antioxidants may be an adjuvant to conventional therapy (such as vasoconstrictors) in the management of sepsis [2, 3].

The heme oxygenases, which consist of inducible and constitutive isozymes (HO-1, HO-2), catalyze the ratelimiting step in the metabolic conversion of heme to the bile pigments (i.e., biliverdin and bilirubin) and thus constitute a major intracellular source of iron and carbon monoxide (CO) [4]. HO-1 is a potentially important stress response protein. $\mathrm{HO}-1$ is induced not only by the substrate heme but also by a variety of nonheme substance such as heavy metals, endotoxin, heat shock, cytokines, and prostaglandins [4]. HO-1 and the subsequent metabolites of heme catabolism appear to play vital roles in regulating important biological responses, including inflammation, oxidative stress, cell survival, and cell proliferation [4]. The proposed mechanisms by which HO-1 exerts its biological effects include its ability to degrade the prooxidative heme, the release of biliverdin and subsequent conversion to bilirubin, both of which have antioxidant properties' and the generation of $\mathrm{CO}$, which has vasodilatory, antiproliferative, and anti-inflammatory properties [4]. At the same time, investigators have provided evidence that $\mathrm{CO}$ via the $\mathrm{HO}$ system may contribute to the regulation 
of systemic blood pressure and partially participate in the hypotensive response to LPS [5]. However, which is more important in aforementioned two behaviors about HO-1 during septic shock is not very clear at present.

To better understand the role of HO-1 in the pathophysiology of septic shock, we evaluated LPS-induced shock and end-organ dysfunction in rats. The goal of the present study was to define the role of HO-1 in LPSinduced hypotension and to determine whether refractory hypotension and/or exaggerated oxidative stress was responsible for the mortality in septic shock rats by $\mathrm{HO}$ activity inhibitor treatment.

\section{Methods}

\section{Animal studies}

Two-month-old male Sprague-Dawley rats (160-185 g) were purchased from the Laboratory Animal Center of Tongji Medical College. Only five animals were housed in the same cage, acclimatized to a 12-h light-dark cycle and allowed free access to food and water for a 5-day period prior to the experimental procedure. During the experiments, the environmental temperature was maintained between 23 and $25^{\circ} \mathrm{C}$. The experimental protocol was approved by the local animal care and use committee, and all animals received humane care according to the criteria outlined in the "Guide for the Care and Use of Laboratory Animals" prepared by the National Academy of Sciences and published by the National Institutes of Health (NIH publication 86-23, revised 1985).

Rats were fasted for $12 \mathrm{~h}$, but allowed free access to water before the induction of anesthesia. The rats received an intraperitoneal injection of $20 \%$ urethane $(1.5 \mathrm{~g} / \mathrm{kg})$ that kept them anesthetized throughout the experiment. The right carotid artery and the intra-jugular vein were cannulated with PE-50 tubing to monitor the mean arterial pressure (MAP) using Hellige monitor instruments (Germany), and with a 24-g cannula for intravenous injections. Subsequently, the animals were heparinized with $500 \mathrm{U} /$ $\mathrm{kg}$ heparin.

Eighty rats were randomly divided into four groups: C group $(n=20), \mathrm{Z}$ group $(n=20)$, SS group $(n=20)$ and $\mathrm{LZ}$ group $(n=20)$. Groups $\mathrm{C}$ and $\mathrm{Z}$ received $0.5 \mathrm{ml}$ normal saline intravenously, while groups SS and LZ both received $0.5 \mathrm{ml}(10 \mathrm{mg} / \mathrm{kg}) \mathrm{LPS}(\mathrm{O} 111 \mathrm{~B} 4$, Sigma, USA) to replicate the experimental model of septic shock. After an initial 25\% decrease in the MAP, group LZ received $1 \mathrm{ml}$ $(10 \mu \mathrm{mol} / \mathrm{kg}$, intraperitoneally) zinc protoporphyrin-IX (ZnPP-IX, Sigma, USA), while group SS received $1 \mathrm{ml}$ $50 \mathrm{mM}$ sodium bicarbonate vehicle in place of ZnPP-IX. Two hours after injecting normal saline intravenously, group $\mathrm{Z}$ received $1 \mathrm{ml}(10 \mu \mathrm{mol} / \mathrm{kg}$, intraperitoneally) ZnPP-IX, while group $\mathrm{C}$ received $1 \mathrm{ml} 50 \mathrm{mM}$ sodium bicarbonate vehicle instead. The rats received $0.5 \mathrm{ml}$ of $30 \mathrm{mg} / \mathrm{kg}$ Evans blue (EB, Serva, Germany) intravenously 5 min before administering the LPS or normal saline. MAP was monitored continuously, and if the MAP did not decrease within $2 \mathrm{~h}$, the animal was excluded from the study.

Monitoring and recording indexes

MAP and ECG were monitored continuously throughout the experiment. The MAP was recorded after the induction of the septic shock at 30,60, 90 and $120 \mathrm{~min}$. And the deaths within $7 \mathrm{~h}$ were recorded.

Sampling and storage

The blood samples were collected $7 \mathrm{~h}$ after LPS administration in a living rat or in a dying rat having an ECG displaying HR $\leq 20$ beats/min, or a ventricular flutter, or a ventricular fibrillation, and centrifuged at $4,000 \mathrm{rpm}$ for $10 \mathrm{~min}$ at $4^{\circ} \mathrm{C}$. The rats were killed, and their femoral artery, liver, lung, and kidney were removed, and quickly perfused with phosphate-buffered saline to remove the blood. The blood samples and the remaining tissues after perfusion and rinsing were frozen in liquid nitrogen and stored at $-70^{\circ} \mathrm{C}$ until assayed.

\section{Biochemical measurements}

Alanine aminotransferase (ALT), aspartate aminotransferase (AST), creatinine (Cr), and blood urea nitrogen (BUN) levels in the plasma were measured with a Hitachi7060 Fully Automated Biochemistry Analyzer (Japan). Hepatic, renal and pulmonary superoxide dismutase (SOD) activity, and malondialdehyde (MDA), contents were determined by spectrophotometry [6] and by the method of Ohkawa et al. [7], respectively. SOD activity and MDA contents were expressed as per unit of protein determined by the Lowry method [8].

\section{Measurement of Evans blue contents}

The right lung was weighed and then incubated in formamide for $18 \mathrm{~h}$ at $37^{\circ} \mathrm{C}$ to extract the EB dye. The left lung was weighed and then dried in an oven at $55^{\circ} \mathrm{C}$, and the wetto-dry weight ratio from that lung was used to estimate the dry weight of the right lung. The extracted dye was quantitated in a spectrophotometer by measuring the absorbance at $620 \mathrm{~nm}$ and comparing to standards of EB dye dissolved in formamide. The EB dye extravasation was expressed as nanograms of EB dye per milligram of dry tissue. 
Measurement of $\mathrm{CO}$ in plasma

CO level in plasma was determined by the method of Chalmers $\mathrm{AH}$ [9], and was expressed as milligram of $\mathrm{CO}$ per liter of fresh blood.

RNA extraction and reverse transcription (RT)-PCR

Total RNA was extracted from the femoral artery, liver, kidney, and lung by employing a Total Quick RNA kit (TA200TQR, Talent, Italy). The ethanol-precipitated RNA fraction $(1 \mu \mathrm{g})$ was reverse transcribed using a Revert Aid $^{\mathrm{TM}}$ First Strand cDNA Synthesis kit (MetaBios Inc., Canada), according to the manufacturer's protocol, and $50 \mu \mathrm{L}$ of first-strand cDNA solution was obtained. The primers used in this study were $5^{\prime}$-CGACAGCATGTCC CAGGATT- $3^{\prime}$ and $5^{\prime}$-TCGCTCTATCTCCTCTTCCAGG-3' for rat HO-1, $160 \mathrm{bp}$; 5'-TTCTACCTGTTCGAGCATG TGG-3' and 5'-TGTTAGCATGGAGCCAGCCT-3' for rat HO-2, 180 bp; 5'-CCTAAGGCCAACCGTAAAG-3' and 5'-TCTTCATGGTGCTAGGAGCCA-3' for rat $\beta$-actin, 623 bp. RT-PCR was performed as described by Hidenori Suzuki et al. [10]. The integral optical density (IOD) of the DNA bands was measured with a Shanghai Sixing Image Analysis System. The IOD ratio of HO-1, or HO-2, and Bactin was calculated, and used as an expression of HO-1 mRNA or HO-2 mRNA.

\section{Western blot analysis}

Tissue samples were homogenized in $13.2 \mathrm{mmol} / \mathrm{L}$ Tris$\mathrm{HCl}$, 5.5\% glycerol, $0.44 \%$ SDS, and 10\% ß-mercaptoethanol. An equal amount of extracted soluble protein $(50 \mu \mathrm{g})$ was fractionated by Tris-glycine-SDS-polyacrylamide gel (12\%) electrophoresis, and Western blotting was performed as described [11] with use of a polyclonal rabbit antibody to recombinant rat $\mathrm{HO}-1$ or $\mathrm{HO}-2$ protein (1:1,000, Santa Cruz, USA). The IOD of protein bands were measured with a LEICA-550IW Image Analysis System. The product of IOD and the area was as an expression of HO-1 protein (or HO-2 protein).
Statistical analysis

All data were expressed as mean \pm standard deviation (SD). Comparisons of mortality between groups were made by the $\chi^{2}$ goodness of fit test, and intergroup comparisons among the four groups were determined by one-way ANOVA. When the $F$ value was significant $(P<0.05)$, a post hoc analysis was performed with the Duncan new multiple range test in order to test the difference between means. $P<0.05$ was considered statistically significant.

\section{Results}

Deaths

The death rate in group SS (13 animals) was lower than that in the LZ group (19 animals) $(P<0.05)$, and was higher than that in groups $\mathrm{C}$ (zero animal) and $\mathrm{Z}$ (zero animal) (all $P<0.05$ ), respectively. There was no significant difference in death rate between $\mathrm{C}$ group and $\mathrm{Z}$ group $(P>0.05)$.

\section{Comparisons of MAP}

The changes of MAP among the four groups are shown in Table 1. Sixty minutes after septic shock, the MAP in the LZ group was significantly higher than that in the SS group (all $P<0.05$ ), and lower than that in groups $\mathrm{C}$ and $\mathrm{Z}$ (all $P<0.05)$. There was no significant difference between the $\mathrm{C}$ group and the $\mathrm{Z}$ group $(P>0.05)$.

Comparisons of $\mathrm{CO}, \mathrm{Cr}$ and Bun concentrations, ALT and AST activities, and lung EB contents

The comparisons of the $\mathrm{CO}, \mathrm{Cr}$ and BUN concentrations, ALT and AST activities, and EB contents among four groups are shown in Table 2. The CO concentration in group LZ was significantly lower than that in group SS $(P<0.05)$, and greater than that in group $\mathrm{C}$ and $\mathrm{Z}$, respectively (all $P<0.05)$. The $\mathrm{Cr}$ and BUN concentrations, ALT and AST

Table 1 Changes of MAP by ZnPP-IX or $\mathrm{NaHCO}_{3}$ treatment in four groups $(\bar{x} \pm s, n=20)$

\begin{tabular}{|c|c|c|c|c|c|c|}
\hline & \multirow[t]{2}{*}{ Basic MAP } & \multirow[t]{2}{*}{ Before treatment MAP $(\mathrm{mmHg})$} & \multicolumn{4}{|c|}{ After treatment MAP $(\mathrm{mmHg})$} \\
\hline & & & $30 \mathrm{~min}$ & $60 \min$ & $90 \mathrm{~min}$ & $120 \mathrm{~min}$ \\
\hline $\mathrm{C}$ & $99.6 \pm 12.2$ & $98.1 \pm 11.1^{*}$ & $97.1 \pm 12.1 *$ & $97.8 \pm 11.8^{*}$ & $98.6 \pm 11.7^{*}$ & $99.1 \pm 10.7 *$ \\
\hline $\mathrm{Z}$ & $100.1 \pm 10.9$ & $98.8 \pm 10.5^{*}$ & $97.4 \pm 11.3^{*}$ & $99.0 \pm 10.6^{*}$ & $99.3 \pm 10.5^{*}$ & $98.2 \pm 12.7 *$ \\
\hline SS & $99.1 \pm 11.7$ & $72.2 \pm 9.3$ & $70.1 \pm 9.2$ & $67.1 \pm 7.8^{*}$ & $65.1 \pm 7.3 *$ & $63.4 \pm 6.8^{*}$ \\
\hline LZ & $98.8 \pm 11.5$ & $72.8 \pm 9.0$ & $70.6 \pm 8.5$ & $72.3 \pm 7.3$ & $73.3 \pm 6.9$ & $74.5 \pm 7.6$ \\
\hline
\end{tabular}

* Indicates test group significantly different from LZ group (one-way ANOVA, $P<0.05$ ) 
Table 2 Comparisons of the Cr and BUN concentrations, ALT and AST activities, and EB contents among four groups $(\bar{x} \pm s, n=20)$

\begin{tabular}{lcccccc}
\hline & Cr $(\mu \mathrm{mol} / \mathrm{L})$ & BUN $(\mathrm{mmol} / \mathrm{L})$ & ALT $(\mathrm{U} / \mathrm{L})$ & AST $(\mathrm{U} / \mathrm{L})$ & EB $(\mathrm{ng} / \mathrm{mg})$ & CO $(\mathrm{mg} / \mathrm{L})$ \\
\hline $\mathrm{C}$ & $92.4 \pm 12.3^{*}$ & $5.9 \pm 1.3^{*}$ & $37.7 \pm 7.3^{*}$ & $49.1 \pm 9.1^{*}$ & $46.7 \pm 9.5^{*}$ & $0.45 \pm 0.06^{*}$ \\
$\mathrm{Z}$ & $94.9 \pm 11.7^{*}$ & $6.1 \pm 1.2^{*}$ & $39.2 \pm 6.9^{*}$ & $51.6 \pm 8.7^{*}$ & $48.2 \pm 8.7^{*}$ & $0.43 \pm 0.08^{*}$ \\
$\mathrm{SS}$ & $120.8 \pm 19.1$ & $11.5 \pm 2.6$ & $66.9 \pm 12.0$ & $105.3 \pm 12.2$ & $230.4 \pm 44.8$ & $0.84 \pm 0.14$ \\
LZ & $135.5 \pm 20.8^{*}$ & $13.4 \pm 2.0^{*}$ & $77.1 \pm 12.8^{*}$ & $115.1 \pm 14.9^{*}$ & $270.6 \pm 51.9^{*}$ & $0.70 \pm 0.11^{*}$
\end{tabular}

* Indicates test group significantly different from SS group (one-way ANOVA, $P<0.05$ )

Table 3 Comparisons of the MDA contents and SOD activity in kidney, lung, and liver among four groups $(\bar{x} \pm s, n=20)$

* Indicates test group significantly different from SS group (1-way ANOVA, $P<0.05)$

\begin{tabular}{lllll}
\hline & C & Z & SS & LZ \\
\hline Kidney & & & & \\
MDA (nmol/mg protein) & $1.57 \pm 0.54^{*}$ & $1.59 \pm 0.51^{*}$ & $2.63 \pm 0.66$ & $3.57 \pm 0.78^{*}$ \\
SOD (NU/mg protein) & $28.4 \pm 2.12^{*}$ & $27.7 \pm 2.38^{*}$ & $14.4 \pm 1.89$ & $12.2 \pm 1.67^{*}$ \\
Lung & & & \\
MDA (nmol/mg protein) & $1.79 \pm 0.55^{*}$ & $1.83 \pm 0.52^{*}$ & $3.62 \pm 0.92$ & $4.33 \pm 1.12^{*}$ \\
SOD (NU/mg protein) & $30.9 \pm 4.4^{*}$ & $31.2 \pm 4.1^{*}$ & $16.8 \pm 2.04$ & $14.2 \pm 1.84^{*}$ \\
Liver & & & \\
MDA (nmol/mg protein) & $9.76 \pm 1.27^{*}$ & $10.1 \pm 1.12^{*}$ & $15.5 \pm 2.3$ & $17.4 \pm 2.9^{*}$ \\
SOD (NU/mg protein) & $68.1 \pm 12.9^{*}$ & $66.4 \pm 13.5^{*}$ & $42.1 \pm 10.3$ & $32.6 \pm 7.2^{*}$ \\
\hline
\end{tabular}

activities, and lung EB contents in group SS were significantly lower than that in group LZ (all $P<0.05$ ), and greater than that in groups $\mathrm{C}$ and $\mathrm{Z}$, respectively (all $P<0.05$ ). There were no significant differences in six indices between the $\mathrm{C}$ group and the $\mathrm{Z}$ group (all $P>0.05$ ).

\section{Comparisons of MDA contents and SOD activity}

The comparisons of the MDA contents and SOD activity in kidney, lung and liver among four groups is shown in Table 3. The nephric, pulmonary, and hepatic MDA contents in groups SS were significantly lower than that in the LZ group (all $P<0.05$ ), and greater than that in the groups $\mathrm{C}$ and $\mathrm{Z}$ (all $P<0.05$ ). The SOD activity was reverse in the four groups, respectively. There were no significant differences in MDA contents and SOD activity between groups $\mathrm{C}$ and $\mathrm{Z}$ (all $P>0.05$ ).

Comparisons of HO-1 mRNA, HO-2 mRNA,

$\mathrm{HO}-1$ protein, and HO-2 protein expression

The comparisons of HO-1 mRNA, HO-2 mRNA, HO-1 protein, and $\mathrm{HO}-2$ protein in femoral arterial, nephric, pulmonary, and hepatic tissue are shown in Tables 4 and 5, and Figs. 1, 2, 3, 4, 5, 6, 7 and 8. The HO-1 mRNA and HO-1 protein of femoral arterial, nephric, pulmonary, and hepatic tissue in groups LZ were lower than that in group SS (all $P<0.05$ ), and greater than that in groups $\mathrm{C}$ and $\mathrm{Z}$ (all $P<0.05$ ). There were no significant differences between groups $\mathrm{C}$ and $\mathrm{Z}$ (all $P>0.05$ ). The HO-2 mRNA and HO-2 protein among four groups were not significantly different (all $P>0.05$ ).

\section{Discussion}

In the present study, the role of $\mathrm{HO}-\mathrm{CO}$ on septic shock in rats was investigated. The principal finding of this study was that the upregulation of $\mathrm{HO}-1$ protein followed by $\mathrm{CO}$ increasing could reduce the mortality during septic shock, while the hypotension partly contributing to HO-1 protein and $\mathrm{CO}$ has no obvious relation with it.

Immunocytochemical staining localizes an increase in HO-1 protein within smooth muscle cells of both large (aorta) and small (arterioles) blood vessels, and the induction of $\mathrm{HO}$ and subsequent $\mathrm{CO}$ could reduce vascular tone during septic shock [12]. To clarify the role of HO induction in septic shock, we administered ZnPP-IX to rats that were made hypotensive by LPS. We used ZnPP-IX instead of other metalloporphyrins to inhibit $\mathrm{HO}$ activity because ZnPP-IX has been shown to be selective for HO over other microsomal enzymes [13]. To avoid effect of ZnPP-IX on NOS activity and soluble guanylyl cyclase activity in vascular endothelial cells, ZnPP-IX was given in a dose of $10 \mu \mathrm{mol} / \mathrm{kg}$ [12] in this study. In our experiments, ZnPP-IX abrogated the LPS-induced hypotension, and it increased the mortality. At the same time, HO- $1 \mathrm{mRNA}$, and $\mathrm{HO}-1$ protein in femoral artery and plasma $\mathrm{CO}$ dramatically decreased.

Downregulation of HO-1 protein by ZnPP-IX in septic shock was found in the liver, lung, and kidney resulting in a 
Table 4 The comparison of HO-1mRNA and HO-2mRNA expression in the femoral arterial, hepatic, renal, and pulmonary tissue among four groups $(\bar{x} \pm s, n=20)$

\begin{tabular}{|c|c|c|c|c|c|c|c|c|}
\hline & \multicolumn{4}{|l|}{ HO-1mRNA } & \multicolumn{4}{|l|}{ HO-2mRNA } \\
\hline & $\mathrm{C}$ & $\mathrm{Z}$ & SS & $\mathrm{LZ}$ & $\mathrm{C}$ & $\mathrm{Z}$ & SS & $\mathrm{LZ}$ \\
\hline Femoral artery & $0.73 \pm 0.10 *$ & $0.71 \pm 0.09 *$ & $1.46 \pm 0.14^{*}$ & $1.10 \pm 0.16$ & $0.97 \pm 0.08$ & $0.99 \pm 0.08$ & $1.02 \pm 0.08$ & $1.02 \pm 0.08$ \\
\hline Kidney & $0.81 \pm 0.12 *$ & $0.79 \pm 0.10^{*}$ & $1.33 \pm 0.15^{*}$ & $1.07 \pm 0.13$ & $1.02 \pm 0.08$ & $0.98 \pm 0.09$ & $0.97 \pm 0.08$ & $1.03 \pm 0.09$ \\
\hline Lung & $0.74 \pm 0.11 *$ & $0.72 \pm 0.10^{*}$ & $1.51 \pm 0.19 *$ & $1.03 \pm 0.14$ & $1.01 \pm 0.07$ & $0.99 \pm 0.06$ & $1.02 \pm 0.07$ & $0.98 \pm 0.05$ \\
\hline Liver & $0.69 \pm 0.13^{*}$ & $0.71 \pm 0.11 *$ & $1.56 \pm 0.17 *$ & $1.04 \pm 0.16$ & $0.99 \pm 0.06$ & $0.98 \pm 0.05$ & $1.01 \pm 0.07$ & $1.02 \pm 0.08$ \\
\hline
\end{tabular}

* Indicates test group significantly different from LZ group (1-way ANOVA, $P<0.05$ )

Table 5 The comparison of HO-1 protein and HO-2 protein expression in the femoral arterial, hepatic, renal, and pulmonary tissue among four groups $(\bar{x} \pm s, n=20)$

\begin{tabular}{|c|c|c|c|c|c|c|c|c|}
\hline & \multicolumn{4}{|l|}{ HO-1 protein } & \multicolumn{4}{|l|}{ HO-2 protein } \\
\hline & $\mathrm{C}$ & $\mathrm{Z}$ & SS & $\mathrm{LZ}$ & $\mathrm{C}$ & $\mathrm{Z}$ & SS & $\mathrm{LZ}$ \\
\hline Femoral artery & $4.12 \pm 1.06^{* *}$ & $4.17 \pm 1.04 *$ & $8.53 \pm 2.27 *$ & $6.51 \pm 1.68$ & $3.83 \pm 1.13$ & $3.78 \pm 1.10$ & $3.82 \pm 1.10$ & $3.92 \pm 0.98$ \\
\hline Kidney & $3.61 \pm 1.11^{*}$ & $3.57 \pm 1.13^{*}$ & $6.88 \pm 1.29^{*}$ & $5.49 \pm 1.20$ & $3.21 \pm 1.07$ & $3.14 \pm 1.00$ & $3.25 \pm 1.09$ & $3.18 \pm 1.02$ \\
\hline Lung & $3.93 \pm 0.99^{*}$ & $3.89 \pm 0.98^{*}$ & $9.78 \pm 1.93^{*}$ & $6.97 \pm 1.67$ & $3.49 \pm 1.07$ & $3.46 \pm 1.05$ & $3.54 \pm 1.03$ & $3.58 \pm 1.07$ \\
\hline Liver & $4.29 \pm 1.13^{*}$ & $4.21 \pm 1.16^{*}$ & $11.56 \pm 2.17 *$ & $9.44 \pm 1.56$ & $3.59 \pm 1.16$ & $3.61 \pm 1.10$ & $3.72 \pm 1.07$ & $3.67 \pm 1.11$ \\
\hline
\end{tabular}

* Indicates test group significantly different from LZ group (1-way ANOVA, $P<0.05$ )

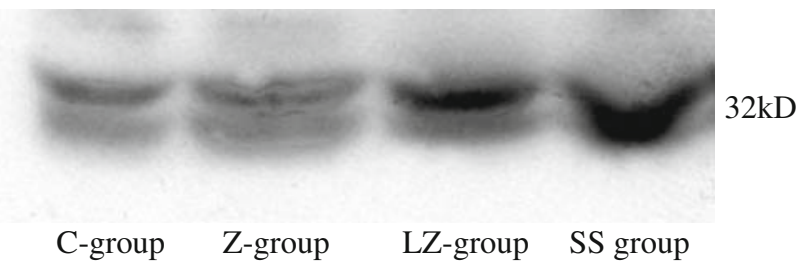

Fig. 1 Western blotting analysis of HO-1 protein in femoral arterial tissue

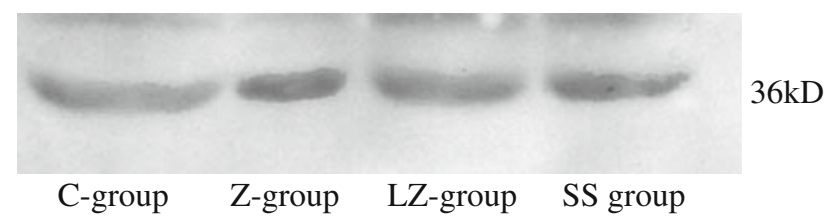

Fig. 2 Western blotting analysis of HO-2 protein in femoral arterial tissue

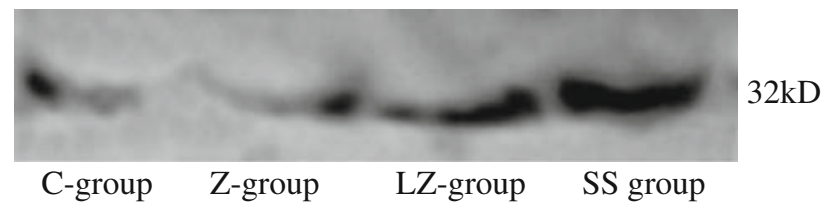

Fig. 3 Western blotting analysis of HO-1 protein in nephric tissue

increasing of the end-organ dysfunctions, and meanwhile CO concentration and SOD activity reduced, and MDA contents and pulmonary vascular leakage increased. Chae and colleagues [14] demonstrated that the inhibition of

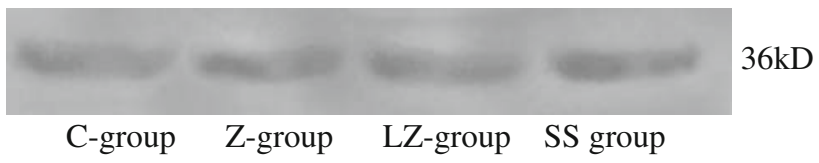

Fig. 4 Western blotting analysis of HO-2 protein in nephric tissue

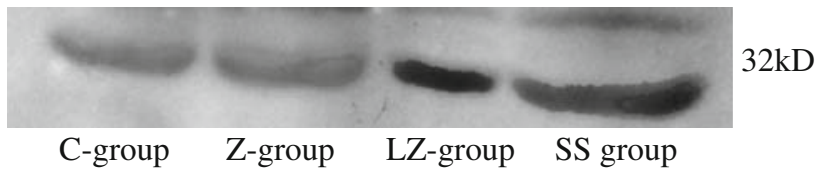

Fig. 5 Western blotting analysis of HO-1 protein in pulmonary tissue

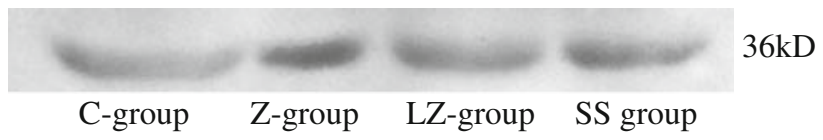

Fig. 6 Western blotting analysis of HO-2 protein in pulmonary tissue

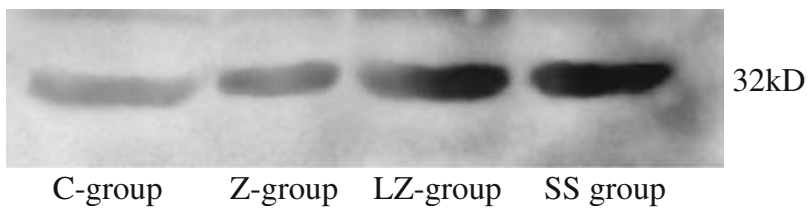

Fig. 7 Western blotting analysis of HO-1 protein in hepatic tissue

HO-1 with using the HO-1 inhibitor ZnPP or HO-1 siRNA resulted in a striking increase of apoptosis in the $\mathrm{CO} / \mathrm{TNF}$ alpha-treated cells. Barrera et al. [15] suggested that HO-1 


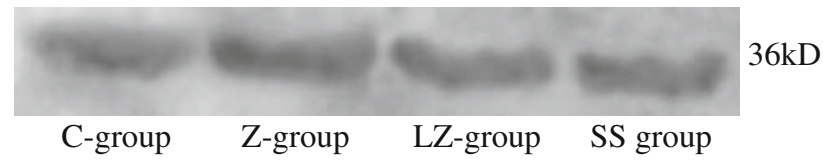

Fig. 8 Western blotting analysis of HO-2 protein in hepatic tissue

overexpression induced by $\mathrm{SnCl}_{2}$ is responsible for the attenuation of renal damage and oxidative stress induced by potassium dichromate. The protective mechanisms of HO-1 may be its augmentation of iron efflux, reflecting a role for HO-1 in modulating intracellular iron levels and regulating cell viability [4]. Bilirubin and biliverdin which are two metabolites of heme degradation, act as scavengers of toxic oxygen radicals. Bilirubin is a strong antioxidant in mammals [16]. CO, a metabolite of heme degradation, can negatively feed back NO generation [4], which can be cytotoxic because of its strong oxidation potential.

This investigation indicated that mortality increased significantly after the septic shock rats treated by ZnPP-IX. ZnPP-IX abrogated the LPS-induced hypotension. The levels of plasma ALT, AST, Cr and BUN, MDA of liver, kidney and lung, and the lung EB contents were significantly increased, while the SOD activity of liver, kidney and lung, and $\mathrm{CO}$ of plasma were reduced. These results indicated that ZnPP-IX treatment could increase MAP and deteriorate the function of liver, kidney, and lung.

Taken together, the increased oxidative stress and endorgan (renal, pulmonary and hepatic) damage is related to the mortality during septic shock, while the hypotension partly contributing to $\mathrm{HO}-1$ protein and $\mathrm{CO}$ has no obvious relation with it. These data also suggest that it is unsuitable to correct refractory hypotension by restraining the $\mathrm{HO}-$ CO system.

Acknowledgments This study was supported in part by Department of Immunology Tongji Medical College, Huazhong University of Science Technology (Boffin Ping Xiong and Boffin Xiaodan Jiang).

Open Access This article is distributed under the terms of the Creative Commons Attribution Noncommercial License which permits any noncommercial use, distribution, and reproduction in any medium, provided the original author(s) and source are credited.
2. Galley HF, Howdle PD, Walker BE (1997) The effects of intravenous antioxidants in patients with septic shock. Free Radic Biol Med 23:768-774. doi:10.1016/S0891-5849(97)00059-2

3. Wang LZ, Zhang QZ, Hu XZ et al (2002) Anti-endotoxic shock effects of cyproheptadine in rats. Chin Med J 115:443-445

4. Ryter SW, Alam J, Choi AM (2006) Heme oxygenase-1/carbon monoxide: from basic science to therapeutic applications. Physiol Rev 86:583-650. doi:10.1152/physrev.00011.2005

5. Chen YH, Yet SF, Perrella MA (2003) Role of heme oxygenase-1 in the regulation of blood pressure and cardiac function. Exp Biol Med 228:447-453

6. Misra HP, Fridovich I (1972) The role of superoxide anion in the autoxidation of epinephrine and a simple assay for superoxide dismutase. J Biol Chem 247:3170-3175

7. Ohkawa H, Ohishi N, Yagi K (1979) Assay for lipid peroxides in animal tissues by thiobarbituric acid reaction. Anal Biochem 95:351-358. doi:10.1016/0003-2697(79)90738-3

8. Lowry OH, Rosebrough NJ, Farr AL et al (1951) Protein measurement with the Folin phenol reagent. J Biol Chem 193: 265-275

9. Chalmers AH (1991) Simple, sensitive measurement of carbon monoxide in plasma. Clin Chem 37:1442-1445

10. Suzuki H, Kanamaru K, Tsunoda H et al (1999) Heme oxygenase-1 gene induction as an intrinsic regulation against delayed cerebral vasospasm in rats. J Clin Invest 104:59-66. doi:10.1172/ JCI5357

11. Sikorski EM, Uo T, Morrison RS et al (2006) Pescadillo interacts with the cadmium response element of the human heme oxygenase-1 promoter in renal epithelial cells. J Biol Chem 281: 24423-24430. doi:10.1074/jbc.M602287200

12. Yet SF, Pellacani A, Patterson C et al (1997) Induction of heme oxygenase-1 expression in vascular smooth muscle cells. A link to endotoxic shock. J Biol Chem 272:4295-4301. doi:10.1074/ jbc.272.7.4295

13. Maines MD (1981) Zinc protoporphyrin is a selective inhibitor of heme oxygenase activity in the neonatal rat. Biochim Biophys Acta 673:339-350

14. Chae HJ, Chin HY, Lee GY et al (2006) Carbon monoxide and nitric oxide protect against tumor necrosis factor-alpha-induced apoptosis in osteoblasts: HO-1 is necessary to mediate the protection. Clin Chim Acta 365(1-2):270-278. doi:10.1016/j.cca. 2005.09.011

15. Barrera D, Maldonado PD, Medina-Campos ON et al (2003) HO1 induction attenuates renal damage and oxidative stress induced by $\mathrm{K}_{2} \mathrm{Cr}_{2} \mathrm{O}_{7}$. Free Radic Biol Med 34(11):1390-1398. doi: 10.1016/S0891-5849(03)00068-6

16. Kapitulnik J (2004) Bilirubin: an endogenous product of heme degradation with both cytotoxic and cytoprotective properties. Mol Pharmacol 66:773-779. doi:10.1124/mol.104.002832

\section{References}

1. Macdonald J, Galley HF, Webster NR (2003) Oxidative stress and gene expression in sepsis. Br J Anaesth 90:221-232. doi: 10.1093/bja/aeg034 